\title{
EVALUATION OF DEGRADATION EFFECT ON INTERCOOLED GAS TURBINE PERFORMANCE OPERATED IN FLEXIBLE MODE
}

\author{
Siddig Dabbashi ${ }^{1}$, Tarak Assaleh ${ }^{2}$, Asia Gabassa ${ }^{3}$ \\ 1,2 Faculty of Engineering, Sabratha University. \\ ${ }^{3}$ Faculty of Engineering, Zawia University. \\ E-mail: siddig.dabbashi@sabu.edu.ly
}

\begin{abstract}
This paper investigates the effect of type and level of degradation in industrial gas turbine components on its performance under flexible operation due to working as a back-up to renewable energy sources (RES). This investigation was carried out for a 2 -shaft $100 \mathrm{MW}$ aeroderivative gas turbine with intercooler. Due to the influence of unpredictable nature of power produced by RES, power plants are now operating in a flexible manner, which will require the operator to either stop operation during high feed-in from renewables or reducing the power output from the power plant to a certain percentage. This in turn has an impact on the gas turbine performance and thermal efficiency, which is also affected by the type and level of degradation of their components compared to the non-degraded gas turbines. In-House performance simulation software (TURBOMATCH), which was developed in Cranfield University, was used to carry out gas turbine performance modelling according to daily flexible operation scenarios for all seasons. These daily operating scenarios, which describe the power settings and ambient conditions for a period of 24 hours, were developed from data obtained from the UK national grid and the meteorology office data base. Different levels of degradation in mass flow and efficiency for low-pressure compressor and high-pressure turbine were applied in this study. Results illustrate an obvious impact of degradation type and level on fuel flow, turbine entry temperature, blade cooling temperature, shaft rotational speed and thermal efficiency for different seasons. This study has resulted in a tool which may be useful to power plant operators in understanding the various operating scenarios according to the criteria they wish to choose.
\end{abstract}

Keywords: gas turbines, renewable energy, gas turbine flexibility, degradation,
Abbreviations
RES Renewable Energy Sources
CCGT Combined Cycle Gas Turbines
TET Turbine Entry Temperature
Tc Turbine Blade Cooling Temperature
PCN Shaft Rotational Speed
HPT High Pressure Turbine 


\section{LPC Low Pressure Compressor}

\section{Introduction}

Gas turbines used in power generation were used to operate in base load condition to provide stable power for long duration, depending on the electricity demand. However, in recent years, this concept has changed due to the wide use of renewable energy sources (RES) contributing to the grid (Bonnie,2015). The amount of power produced by RES especially from wind and solar farms is largely unpredictable and erratic, depending on weather conditions, resulting in varying demand on the conventional combined cycle gas turbines (CCGT) that work as back-up to the RES (DECC,2013). Figure (1) illustrates the variation in wind energy generation during January 2013 in the UK, which resulted in CCGT power plants to operate in flexible mode, in order to be used as a back-up to RES. Figure (2) shows an obvious daily variation in power produced in the UK from CCGT power plants (BM, UK \&National Grid Status, 2014).

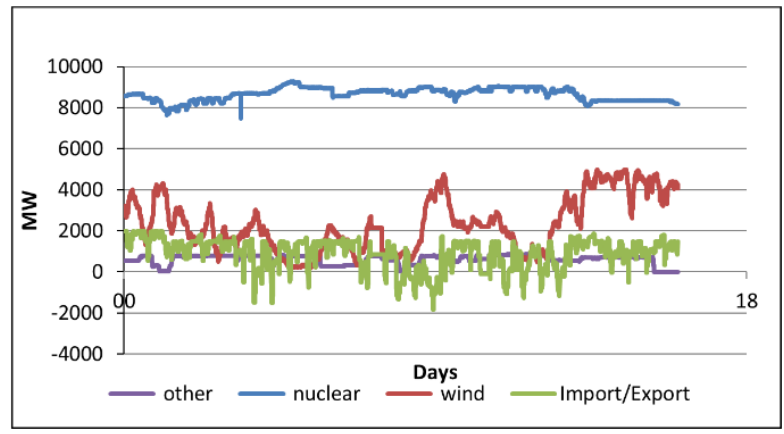

Figure (1): UK power generation from non-peaking plants (January 2013) [3]

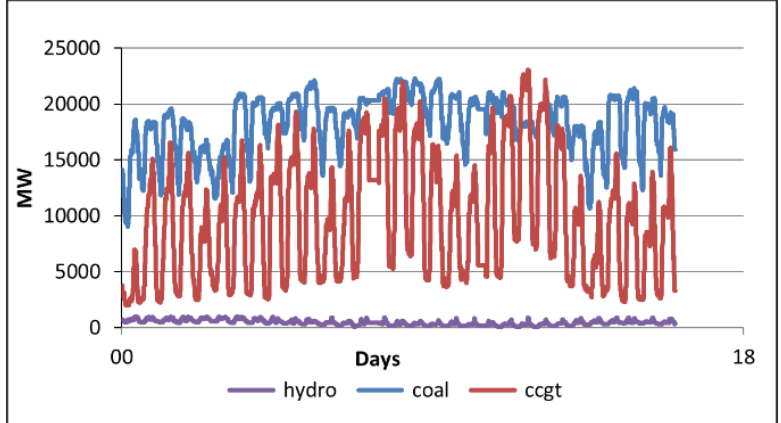

Figure (2): UK power generation from peaking plants (January 2013) [3]

The flexible operations of CCGTs would affect their performance, life, emissions and economics (Ghafir et al, 2010). Thus, it is imperative for the CCGT operators to understand this impact, in order to be able to manage the operation of their power plants. It is necessary to investigate the impact of operation flexibility taking into account these features. Operational flexibility (flexibility in plant operation), which means variable power setting of gas turbines (GT) during the day depending on the load demand, combined with a variation in ambient conditions leads to a variation in air mass-flow, fuel mass-flow, turbine entry temperature (TET), shaft rotational speed (PCN), efficiency, etc. This variation in performance parameters has a direct impact on the 
GT life, the amount of emissions produced and the cost of electricity generated (Ghafir et al, 2010).

Gas turbines installed in existing power plants degrade with time due to fouling, corrosion, erosion, etc. This degradation adversely affects their performance parameters, which in turn could affect the HPT blades creep and LCF life (Kassim, 2013).

\section{Degradation in Gas Turbines}

Industrial gas turbines are designed to operate according to the manufacturer's performance specifications. However, after a certain period of operation, the performance of the engine begins to decrease due to components deterioration (Lakshminarasimha, et al,1994). Even operating under normal conditions (good inlet filters, clean fuel, etc.) the engine flow path components could be affected by fouling, erosion, corrosion and covering with scale (Diakunchak, 1992). This will affect the overall performance of the gas turbine including the thermal efficiency, and power output. In order to generate the required power, the degraded engine needs to work with higher fuel consumption, turbine entry temperature and shaft rotational speed which certainly result in higher operating cost and lower creep and low cycle fatigue life of turbine blades (Malik ,2013). Deterioration in gas turbine can be classified into recoverable, non-recoverable and permanent (Kassim, 2013).

\section{Recoverable Gas Turbine Deterioration}

This type of deterioration can be recovered by cleaning or washing, where the majority of gas turbine deterioration can be found (Malik, 2013). Fouling is the most common type of recoverable deterioration. "Fouling is defined as degradation of flow capacity and efficiency, caused by the adherence of particular contaminants to the gas turbine's airfoil and annulus surfaces" (Diakunchak, 1992). Even in normal operating conditions, using air filters, GT accumulates dirt, dust, salt, pollen, etc. in the compressor figure (3) and gas path surfaces. Despite the fact that the compressor ingests the contaminants, the turbine has its own degradation environments, which are combustion products. Combustion products sometimes block the cooling paths. Furthermore, some contaminants passing through the compressor become molten due to high TET and stick to the turbine blades causing turbine fouling (Malik ,2013). Operating conditions of industrial gas turbines in an environment that almost contains impurities are the major cause of fouling in addition to internal oil leaks near the blade surfaces (Lakshminarasimha, et al,1994). 


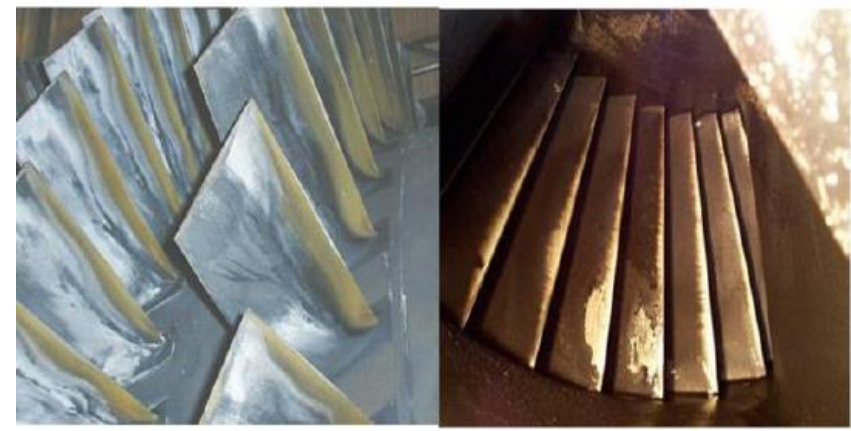

Figure (3): Contaminants deposits on the compressor blades [6]

\section{Non-Recoverable Gas Turbine Deterioration}

Some mechanical problems such as erosion, corrosion, cooling passage plugging, or foreign object damage, results in deterioration of some components, which cannot be recovered by cleaning or washing. This kind of deterioration is called non-recoverable and requires replacement of these components, through engine repair or overhaul. This damage causes performance degradation due to the change in components shape or surface roughness (Bonnie, 2015).

Corrosion in gas turbine engines occurs due the chemical reaction between gas turbine components and operating fluid stream. Ingestion of steam, salts, wet acid deposits and some violent gases by the gas turbine compressor results in cold corrosion, especially for the gas turbines operating in offshore environment due to the high relative humidity ensuring the salt crystals to be in their wet form. This kind of corrosion results in an increase in the surface roughness of the blades and changes their shape which in-turn decreases compressor performance and blade life (Malik, 2013).

Impurities from ingested air like salts (sodium chloride) react with sulphur content from fuel at elevated temperature during combustion process producing sodium sulphate in the hot gas path. This accelerates the oxidation or sulphidation of turbine nozzle and blades causing hot corrosion. Furthermore, fuel impurities in the hot gas path could increase the hot corrosion of the nozzle and blades which could result in lower performance and shorter life of turbine blades (Kassim, 2013).

Erosion of compressor blades and stator is a result of ingestion of hard abrasive particles such as sand or mineral dusts in gas turbine engines figure (4) (Kassim, 2013), especially when these particles exceed $10 \mu \mathrm{m}$ in diameter (Malik, 2013). "Erosion is defined as the abrasive removal (pitting or cutting) of material from the flow path by hard or incompressible particles impinging on flow surface" (Malik, 2013). 


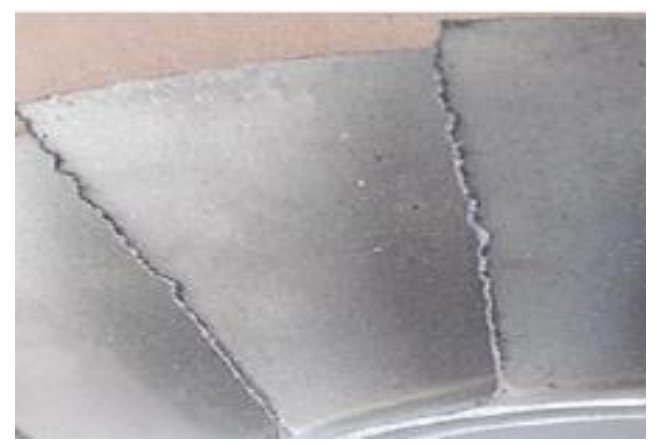

Figure (4): Compressor blade erosion [7]

Erosion occurs mostly in turbines due to combustion products, especially when using a fuel of low quality that contains traces of metal figure (5). However, the erosion rate in turbines is higher than in compressors due to the higher flow rate and the larger angle of blade position to the turbine flow path (Malik, 2013). Erosion in compressor and turbine blades results in increased surface roughness, sharpened trailing edges, blunted leading edges and reduced blade chords (Hamed \& Tabakoff, 2006).

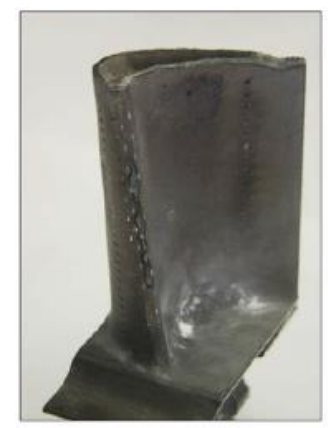

Figure (5): Turbine blade erosion [7]

Air flows through small passages and holes inside the turbine blades and the combustor liner for cooling and protecting them from high temperature. Any contaminants ingested by the compressor could enter these passages and holes causing cooling passage plugging figure (6) that prevents or reduces the flow of cooling air, which can lead to an increase in component temperature leading to thermal cracking (Kassim, 2013). 


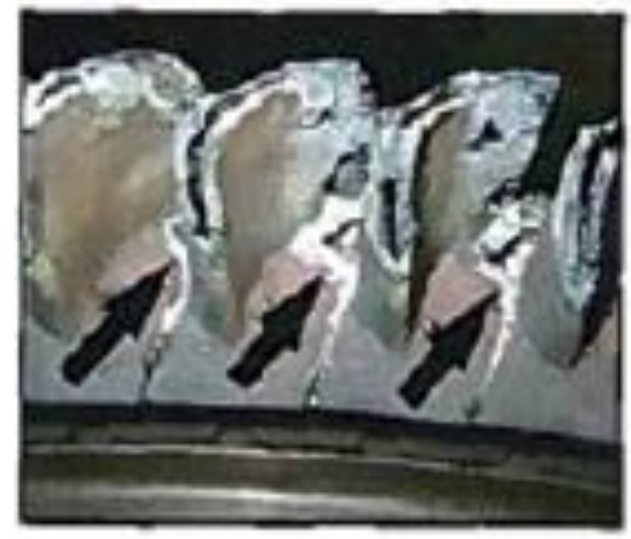

Figure (6): Cooling passage blockage of turbine blade [6]

If large objects are ingested by the compressor due to poor filtration, they cause a nonrecoverable damage in compressor blades especially at the front stages of the compressor figure (7). This damage is called foreign object damage (FOD) and could result in domestic object damage (DOD) (Sugliano \& Pilidis, 2005).

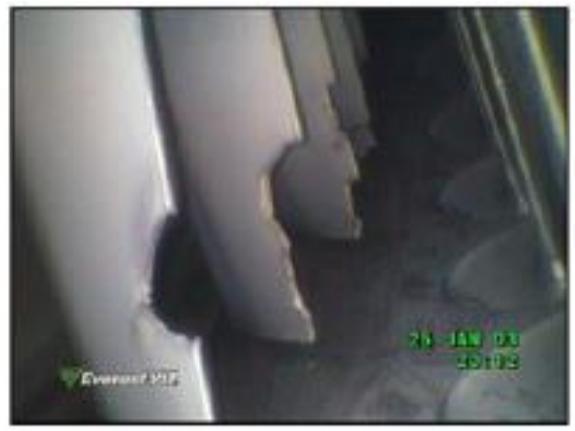

Figure (7): Foreign object damage in compressor blades [11]

\section{Permanent Gas Turbine Deterioration}

Engine overhaul includes cleaning of flow path components, replacement of damaged parts, restoring of any tip and seal clearances, sealing up any obvious leakage path and recoating of pertinent airfoils. After carrying out this process, the engine is assumed to be in "As new and clean" condition and recovers its original performance. However, usually the engine cannot restore the initial test performance, due to some permanent damage in some components such as cylinder distortion, airfoil untwist, distortion in platforms leading to increased leakage and lower aerodynamic performance, increased surface roughness of flow path components because of corrosion and erosion, etc. All these damages that cannot be recovered result in permanent deterioration in gas turbine engines (Diakunchak, 1992). 


\section{Research methodology}

\section{Case study Gas Turbine Model}

An intercooled 100MW two-shaft aero-derivative engine with a configuration as shown in figure (8) is selected as a case study gas turbine. Performance parameters at design point are illustrated in table (1).

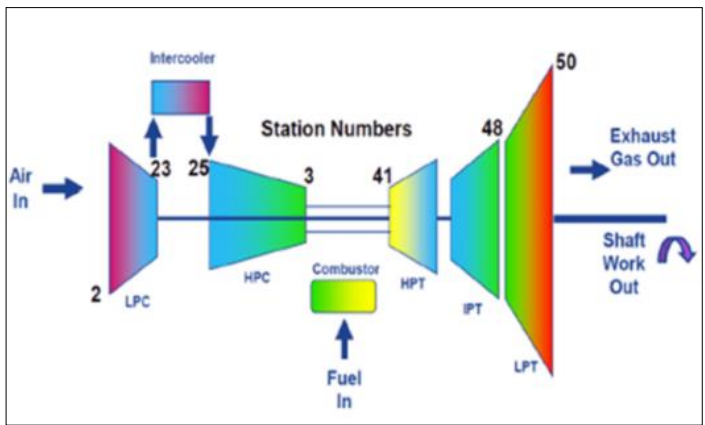

Figure (8): Intercooled 2-shaft gas turbine engine

Table (1): Engine Performance Data

\begin{tabular}{|c|c|}
\hline Parameters & Value \\
\hline Power Output (MW) & 100 \\
\hline Firing Temperature (K) & 1630 \\
\hline Efficiency (\%) & 44 \\
\hline Mass Flow (Kg/s) & 216 \\
\hline Pressure Ratio & 42 \\
\hline
\end{tabular}

\section{Performance Simulation Module}

The performance simulation and engine modelling is carried out using In-House software TURBOMATCH, which is a component based gas turbine performance simulation tool developed at Cranfield University. TURBOMATCH models an engine performance at both design point (DP) and a range of possible off-design conditions (OD) that are usually experienced based on ambient conditions and power setting (Ghafir, 2011). TURBOMATCH was used to simulate a certain operating scenario for a certain gas turbine in a certain ambient condition. This module provides values of different performance parameters such as turbine entry temperatures (TET), HPT blade cooling temperatures (Tc), rotor shaft rotational speeds and fuel flow. The performance results from the code are used as an input for the stress analysis and thermal modules. 


\section{GT Daily Operating Scenarios}

According to data obtained from (UK National Grid Status, 2014) regarding CCGT power plants daily generation in different days during each season, figure (9) has been created. This figure shows the variation in power demand in CCGT power plants during the day for each season in 2014, which shows that the average CCGT daily peak demand is about 18GW that appears in summer and winter days, whereas the lowest demand occurs in winter nights by less than 4GW. High CCGT demand in winter occurs due to the need for domestic heating in the evening, and in summer days due to the shortage of RES production. Spring and autumn have lower peak demand values because domestic heating requirements are lower. The greatest demand variation appears in winter days, which is less than $4 \mathrm{MW}$ at 5:00 am and more than 18GW at the evening (from $25 \%$ to $100 \%$ ), whereas the smallest variation occurs in summer days, which ranges from 9MW to more than 18MW (from $50 \%$ to $100 \%$ ).

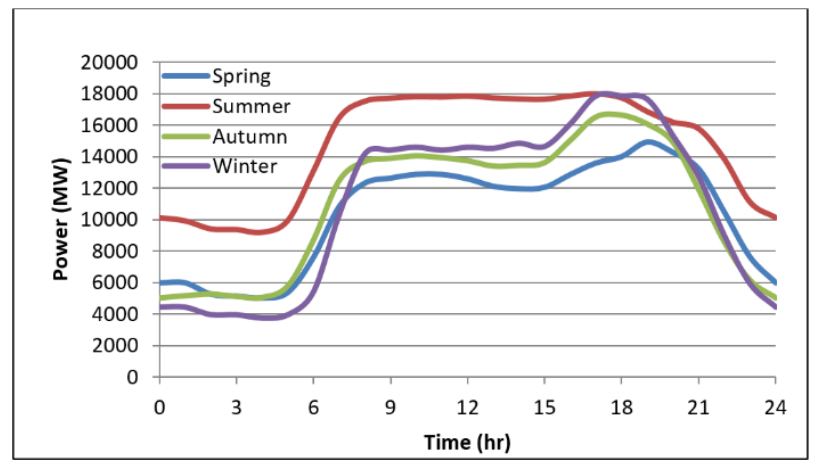

Figure (9): UK daily CCGT average power demand (2014)

Daily ambient conditions vary according to season. According to data obtained from the midlands (Birmingham) as an average of the UK (wunderground,websit). Figure (10) has been created. This figure illustrates the variation in ambient temperatures during the day for each season in 2014, which shows that the variation in average temperatures during the year is from $3^{\circ} \mathrm{C}$ in winter nights to $20^{\circ} \mathrm{C}$ in summer days.

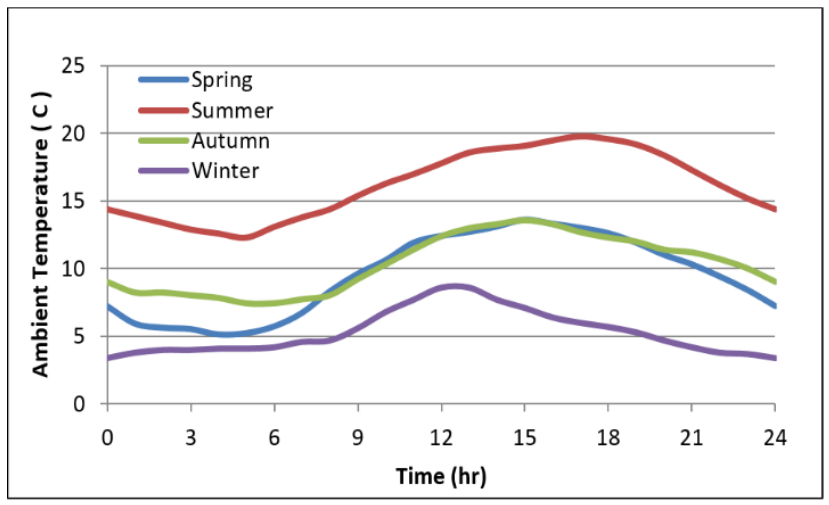

Figure (10): UK daily average ambient temperatures (2014) 
Daily operating scenarios for each GT in a power plant consists of a fleet of 100MW GTs has been created for each season. These scenarios are created according to data presented in figures (9) and (10). Figure (11) illustrates these scenarios of 100MW GT for each season. These scenarios are based on 24 hours operation in a flexible mode to work as a back-up to renewable energy sources. For all seasons, the power generation is clearly lower in the night than the day hours when the demand is higher. Furthermore, spring, autumn and winter scenarios have an evening peak due to domestic heating, which appears significantly in the winter. The minimum load occurs in winter nights with $25 \mathrm{MW}$, which represents $25 \%$ of $100 \mathrm{MW}$ GT capacity, whereas the maximum load occurs in summer day and winter evening with $100 \mathrm{MW}$, which represents $100 \%$ of the capacity. Ambient temperatures during 24 hours are also considered for all seasons.

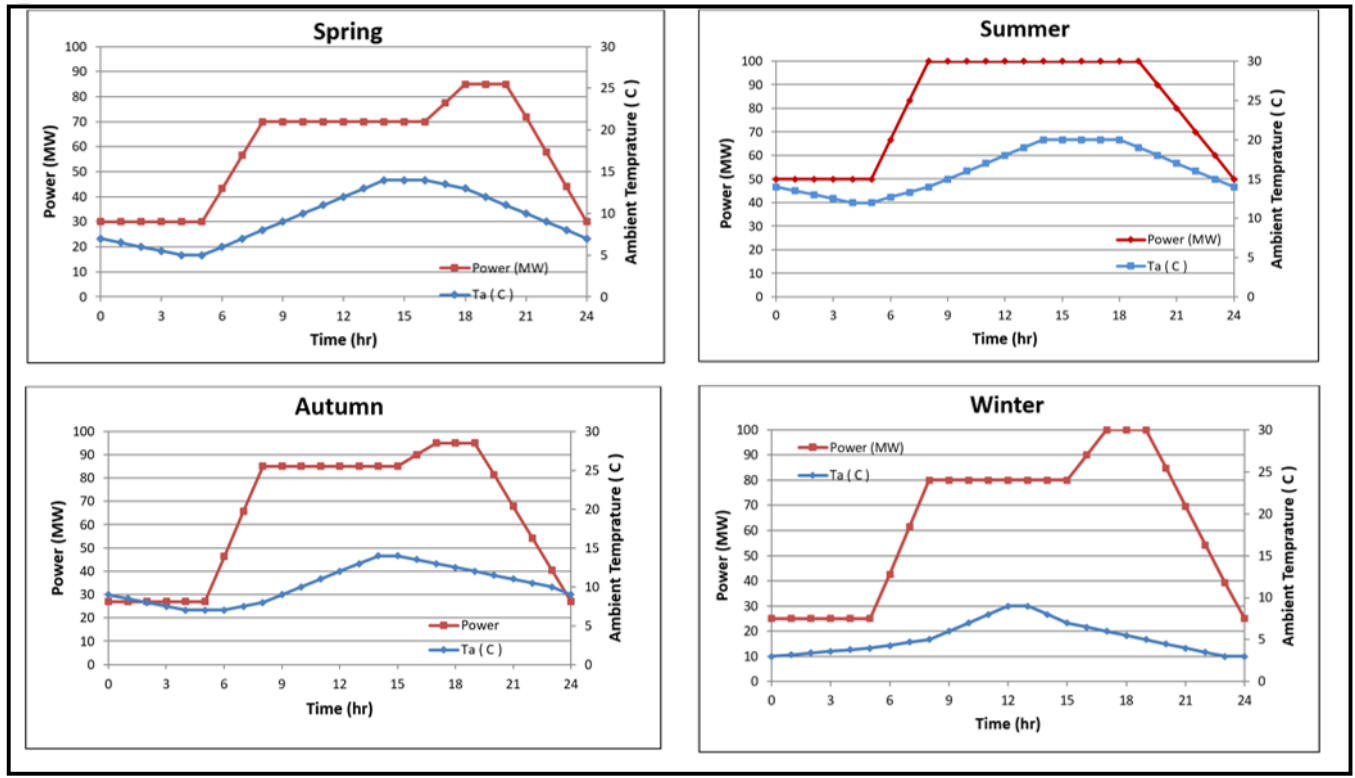

Figure (11): Seasonal daily operating scenarios

\section{Results}

\section{Performance Simulation Results}

In order to investigate the influence of components degradation on a 100MW GT performance and life consumption, two different types of degradation for two different components have been taken in account for all seasonal daily operating scenarios. These types of degradation can be concluded in the following cases:

- From 0\% to 4\% degradation levels in mass flow and component efficiency for both LowPressure-Compressor (LPC) and High-Pressure-Turbine (HPT).

- From $0 \%$ to $4 \%$ degradation levels in mass flow and the component efficiency for LowPressure-Compressor (LPC) only. 
Effect of degradation in both LP Compressor and HP Turbine on GT performance.

GT Performance simulation was carried out using TURBOMATCH for a 100MW GT according to seasonal daily operating scenarios, taking into account different levels of degradation in mass flow and component efficiency for both LPC and HPT. Performance results of spring daily operating scenario are illustrated in figures (12) and (13). Figure (12) shows degradation effect on HPT entry temperatures (TET), HPT blade cooling temperatures (Tc) and HPT shaft rotational speeds $(\mathrm{PCN})$ during 24 hours according to the described spring daily operating scenario and ambient temperatures. Figure (13) illustrates degradation effect on GT efficiency and fuel flow during 24 hours.

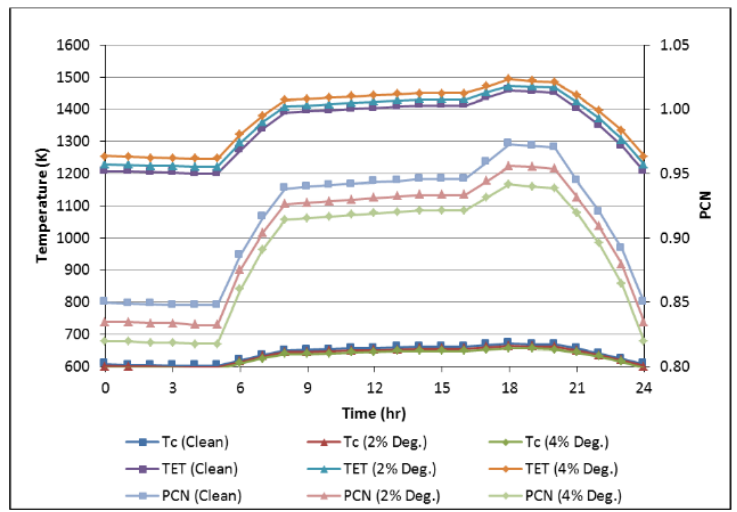

Figure (12): Spring daily Tc, TET and PCN

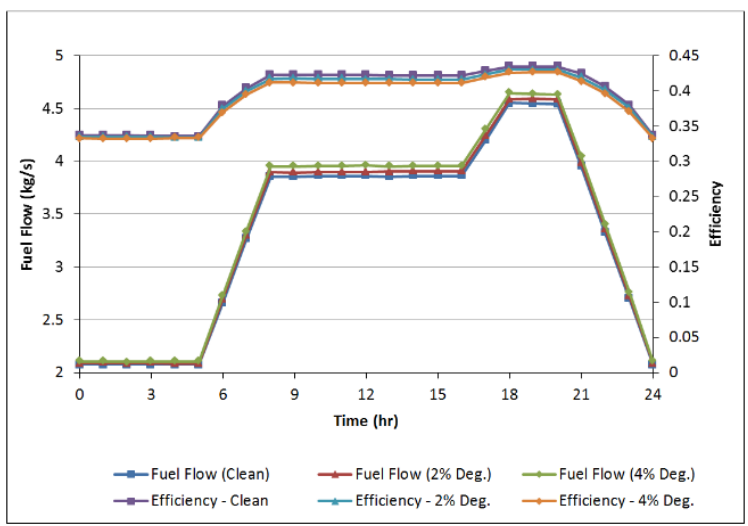

Figure (13): Spring daily fuel flow and efficiency

Figures (14), (16), and (18) illustrates daily TET, Tc and PCN values for summer, autumn and winter respectively. Whereas, figures (15), (17) and (19) shows daily GT efficiency and fuel flow values for these seasons. 


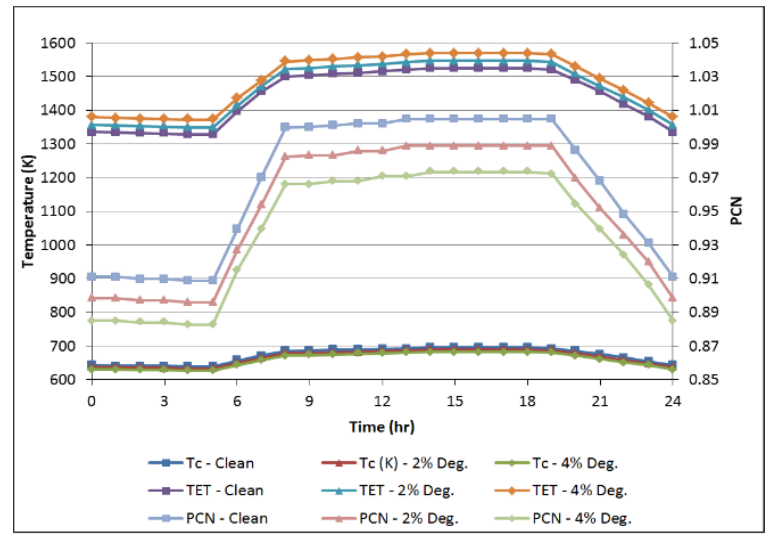

Figure (14): Summer daily Tc, TET and PCN

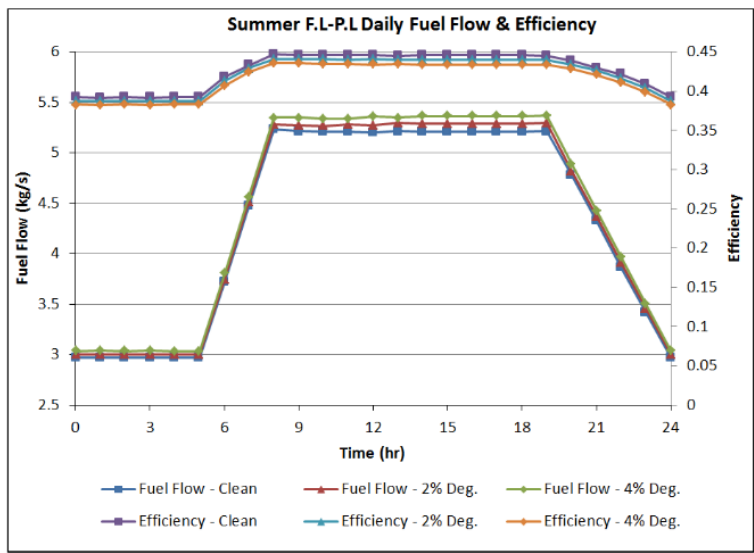

Figure (15): Summer daily fuel flow and efficiency

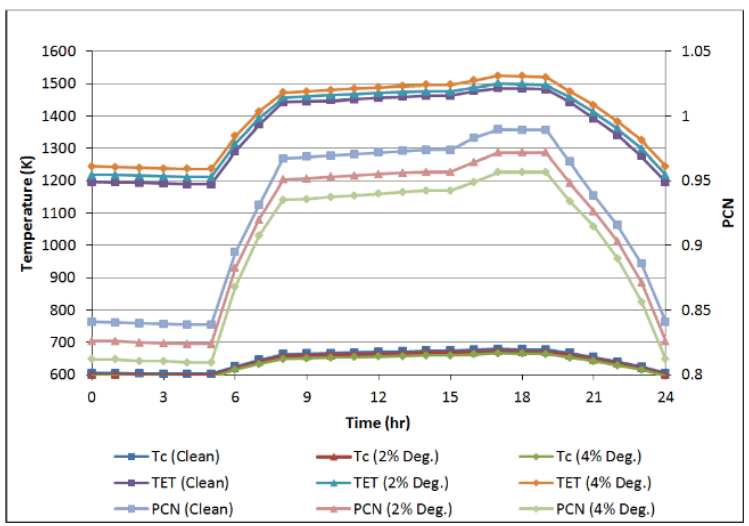

Figure (16): Autumn daily Tc, TET and PCN 


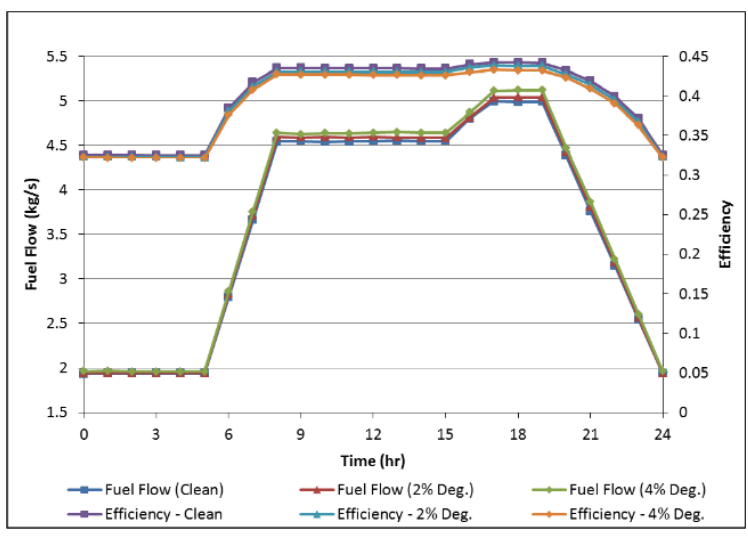

Figure (17): Autumn daily fuel flow and efficiency

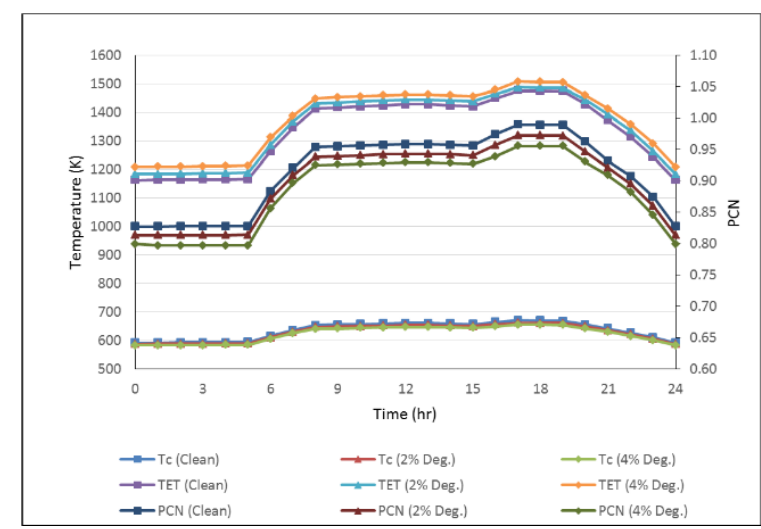

Figure (18): Winter daily Tc, TET and PCN

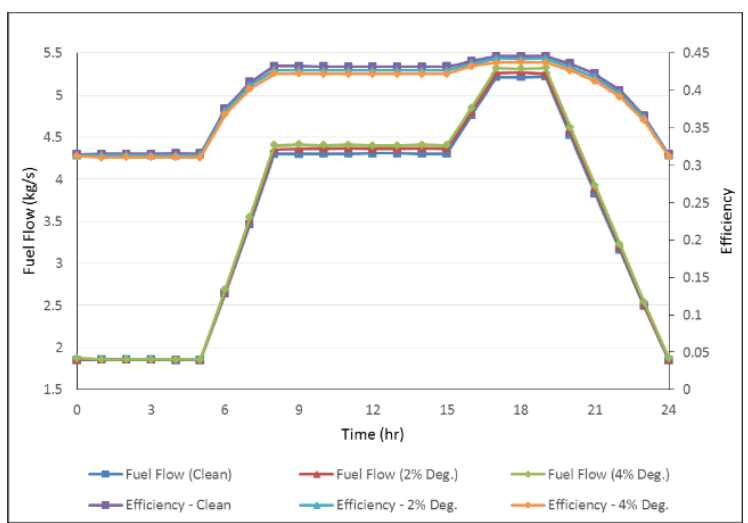

Figure (19): Winter daily fuel flow and efficiency

In general, performance results for all seasons show a significant influence of power setting, ambient temperature and degradation level on TET, PCN, fuel-flow and efficiency values and a slight influence on Tc values. Power setting has a positive correlation with all these performance parameters, whereas ambient temperature has a positive correlation with Tc, TET, PCN and fuelflow, and a negative correlation with GT efficiency. Regarding the effect of the degradation in 
LP compressor and HP turbine, the results show that the more these components are degrading, the higher values of TET and fuel-flow the gas turbine obtains. However, shaft rotational speed (PCN) and Tc are affected negatively by the degradation level. The greater the degradation level the GT components have, the lower PCN and Tc values are produced.

The maximum values of TET in the spring occur at 6:00 pm, when the power generated is in its maximum daily value (85 MW) and the ambient temperature is $13^{\circ} \mathrm{C}$ as shown in figure (16). These values are $1459 \mathrm{~K}, 1473 \mathrm{~K}$ and $1493 \mathrm{~K}$ for clean GT, $2 \%$ degraded GT and $4 \%$ degraded GT respectively. This time of spring day also has the maximum values of PCN, which are 0.973 , 0.956 and 0.941 for clean, 2\% degraded and 4\% degraded GTs respectively. Tables 2 and 3 illustrate daily maximum and minimum values of performance parameters for all seasons.

Table (2): Maximum values of daily performance parameters

\begin{tabular}{|c|c|c|c|c|c|}
\hline \multicolumn{2}{|c|}{ Season } & Spring & Summer & Autumn & Winter \\
\hline \multicolumn{2}{|c|}{ Time } & 18:00 & $16: 00$ & $15: 00$ & 15.00 \\
\hline \multicolumn{2}{|c|}{ Power (MW) } & 85 & 100 & 95 & 100 \\
\hline \multicolumn{2}{|c|}{ Ambient Temperature $\left({ }^{\circ} \mathrm{C}\right)$} & 13.0 & 20.0 & 13.0 & 6.0 \\
\hline \multirow{3}{*}{ Tc $(\mathbf{K})$} & Clean GT & 672 & 695 & 679 & 670 \\
\hline & 2\% Degraded GT & 665 & 689 & 672 & 662 \\
\hline & 4\% Degraded GT & 658 & 683 & 666 & 656 \\
\hline \multirow{3}{*}{ TET $(\mathbf{K})$} & Clean GT & 1459 & 1524 & 1486 & 1477 \\
\hline & 2\% Degraded GT & 1473 & 1547 & 1501 & 1489 \\
\hline & 4\% Degraded GT & 1493 & 1570 & 1524 & 1509 \\
\hline \multirow{3}{*}{ PCN } & Clean GT & 0.97292 & 1.0047 & 0.98964 & 0.98975 \\
\hline & 2\% Degraded GT & 0.95588 & 0.98886 & 0.97177 & 0.97257 \\
\hline & 4\% Degraded GT & 0.94133 & 0.97336 & 0.95653 & 0.95546 \\
\hline \multirow{3}{*}{ Fuel Flow (Kg/s) } & Clean GT & 4.553 & 5.2344 & 4.9959 & 5.215 \\
\hline & 2\% Degraded GT & 4.5892 & 5.292 & 5.0341 & 5.265 \\
\hline & 4\% Degraded GT & 4.6475 & 5.363 & 5.1126 & 5.3177 \\
\hline \multirow{3}{*}{ Efficiency (\%) } & Clean GT & 43.4 & 44.6 & 44.2 & 44.6 \\
\hline & 2\% Degraded GT & 43 & 44 & 43.9 & 44.3 \\
\hline & 4\% Degraded GT & 42.6 & 43.4 & 43.3 & 43.8 \\
\hline
\end{tabular}


Table (3): Minimum values of daily performance parameters

\begin{tabular}{|c|c|c|c|c|c|}
\hline \multicolumn{2}{|c|}{ Season } & Spring & Summer & Autumn & Winter \\
\hline \multicolumn{2}{|c|}{ Time } & $5: 00$ & 5:00 & 5:00 & 00:00 \\
\hline \multicolumn{2}{|c|}{ Power (MW) } & 30 & 50 & 27 & 25 \\
\hline \multicolumn{2}{|c|}{ Ambient Temperature $\left({ }^{\circ} \mathrm{C}\right)$} & 5.0 & 12.0 & 7.0 & 3.0 \\
\hline \multirow{3}{*}{ Tc $(\mathrm{K})$} & Clean GT & 602 & 639 & 602 & 592 \\
\hline & 2\% Degraded GT & 597 & 633 & 597 & 587 \\
\hline & 4\% Degraded GT & 593 & 627 & 592 & 583 \\
\hline \multirow{3}{*}{ TET (K) } & Clean GT & 1200 & 1329 & 1189 & 1162 \\
\hline & 2\% Degraded GT & 1221 & 1349 & 1211 & 1184 \\
\hline & 4\% Degraded GT & 1246 & 1372 & 1236 & 1209 \\
\hline \multirow{3}{*}{ PCN } & Clean GT & 0.84747 & 0.90881 & 0.83857 & 0.82697 \\
\hline & 2\% Degraded GT & 0.83213 & 0.89606 & 0.82384 & 0.8132 \\
\hline & 4\% Degraded GT & 0.81757 & 0.88278 & 0.80955 & 0.79934 \\
\hline \multirow{3}{*}{ Fuel Flow (Kg/s) } & Clean GT & 2.0779 & 2.9676 & 1.9382 & 1.8514 \\
\hline & 2\% Degraded GT & 2.0835 & 2.9973 & 1.9435 & 1.8609 \\
\hline & 4\% Degraded GT & 2.1048 & 3.0333 & 1.9594 & 1.8767 \\
\hline \multirow{3}{*}{ Efficiency (\%) } & Clean GT & 33.6 & 39.2 & 32.5 & 31.5 \\
\hline & 2\% Degraded GT & 33.4 & 38.8 & 0.32 .3 & 31.3 \\
\hline & 4\% Degraded GT & 33.3 & 38.3 & 0.32 .1 & 31.2 \\
\hline
\end{tabular}

\section{Effect of degradation in LP Compressor on GT performance:}

Taking to account the different levels of degradation in mass flow and the component efficiency in the Low-Pressure-Compressor (LPC), GT performance simulation was carried out using TURBOMATCH for a 100MW GT according to summer and winter seasonal daily operating scenarios. Performance results of summer daily operating scenario are illustrated in figures (20) and (21). Figure (20) shows degradation effect on HPT entry temperatures (TET) during 24 hours, whereas figure (21) illustrates degradation effect on shaft rotational speed (PCN) during 24 hours. Figures (22) and (23) show degradation effect on TET and PCN respectively for winter daily operating scenario. 


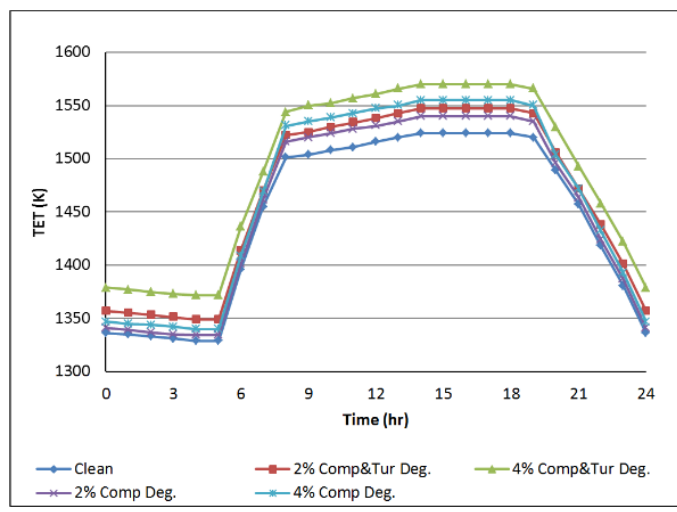

Figure (20): Daily effect of degradation in LPC and degradation in LPC \& HPT on TET (Summer)

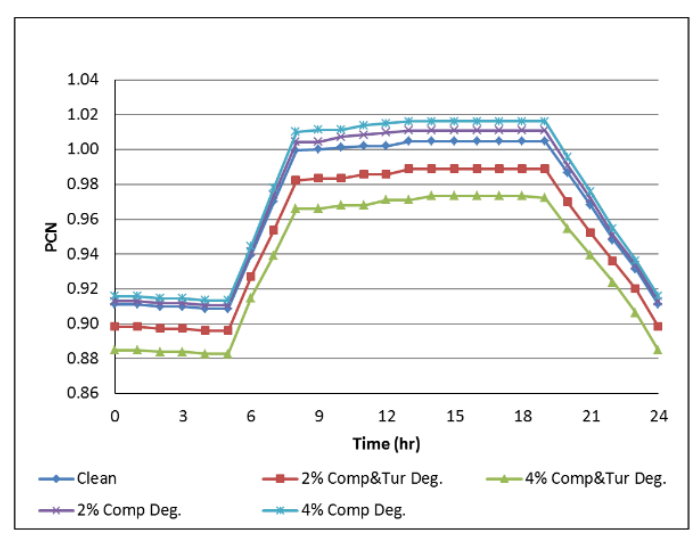

Figure (21): Daily effect of degradation in LPC and degradation in LPC \& HPT on PCN (Summer)

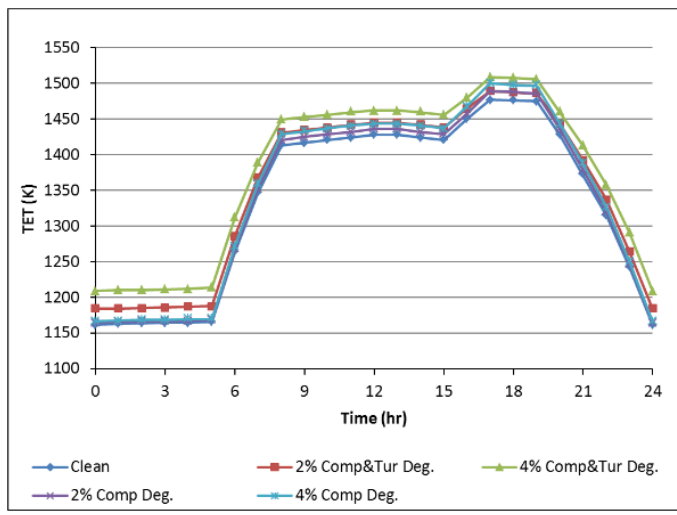

Figure (22):Daily effect of degradation in LPC and degradation in LPC \& HPT on TET (Winter) 


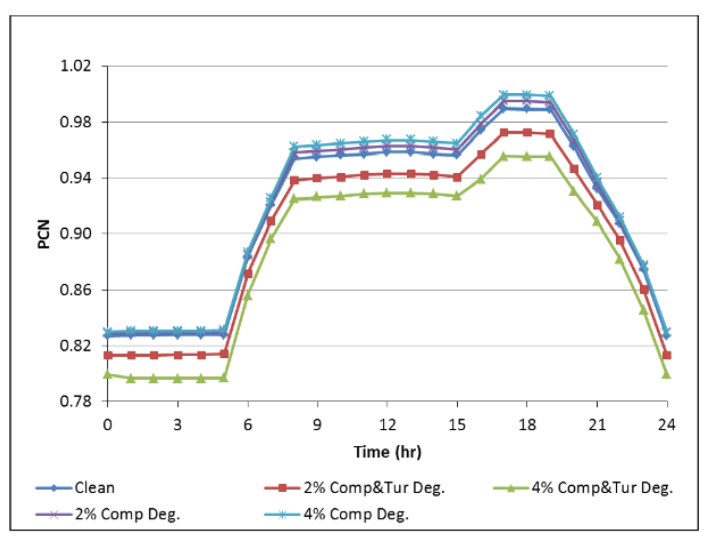

Figure (23): Daily effect of degradation in LPC and degradation in LPC \& HPT on PCN (Winter)

Results show a similar effect of both types of degradation on Turbine-Entry-Temperatures (TET) and an obvious difference in the effect on shaft rotational speeds (PCN). TET increases if there is an increase in degradation level in LPC, or if there is an increase in degradation level in both LPC and HPT, whereas PCN has a positive correlation with the degradation level if the degradation exists in LPC only and it has a negative correlation if the degradation exists in both LPC and HPT. Hence, it can be observed that the highest values of TET occur at the condition of highest level of degradation in both LPC and HPT, and the lowest values of TET occur at the condition of non-degraded GT (Clean). Regarding PCN values, it can be seen that the highest values occurs at the highest level of degradation in LPC, whereas the lowest values occur at the highest level of degradation in both LPC and HPT.

In summer, the maximum daily values of TET occur at 4:00 pm when the power setting is at its maximum value $(100 \mathrm{MW})$, and the ambient temperature is $20^{\circ} \mathrm{C}$. They are $1570 \mathrm{~K}$ and $1555 \mathrm{~K}$ for $4 \%$ degradation in LPC and HPT and 4\% degradation in LPC respectively compared to $1524 \mathrm{~K}$ for the non-degraded GT. This resulted in an increase by $46 \mathrm{~K}$ in daily maximum TET if there is $4 \%$ degradation in mass-flow and efficiency in both LPC and HPT compared to the nondegraded GT. This increase is $31^{\circ} \mathrm{K}$ if there is $4 \%$ degradation in mass-flow and efficiency is in LPC. PCN maximum values also occur at the same time. However, GT with $4 \%$ degradation in LPC has the highest daily maximum value with 1.016, and GT that has $4 \%$ degradation in both LPC and HPT has the lowest maximum value with 0.97 compared to 1.005 for clean GT. Thus, $4 \%$ degradation of mass-flow and efficiency in LPC causes an increase in PCN by 0.011 , whereas $4 \%$ degradation of mass-flow and efficiency is in both LPC and HPT causes a decrease in PCN by 0.008 .

In winter, results show similar effect of degradation in both LPC and HPT, and LPC on TET and PCN highest values during the day that occur at 5:00 pm when the power setting is 100MW and ambient temperature is $6^{\circ} \mathrm{C}$. There is an increase in daily maximum TET by $32 \mathrm{~K}$ if there is $4 \%$ degradation in mass-flow and efficiency in both LPC and HPT, and by $23 \mathrm{~K}$ if there is $4 \%$ degradation in mass-flow and efficiency in LPC compared to non-degraded GT. The 4\% degradation in mass-flow and efficiency on the LPC cause an increase in PCN by 0.01, whereas 
4\% degradation of mass-flow and efficiency is in both LPC and HPT causes a decrease in PCN by 0.035 . Table 4 illustrates the effect of type and level of degradation in 100MW GT on maximum daily values of TET and PCN in typical summer and winter days.

Table (4): Effect of degradation level and type on maximum daily values of TET and PCN

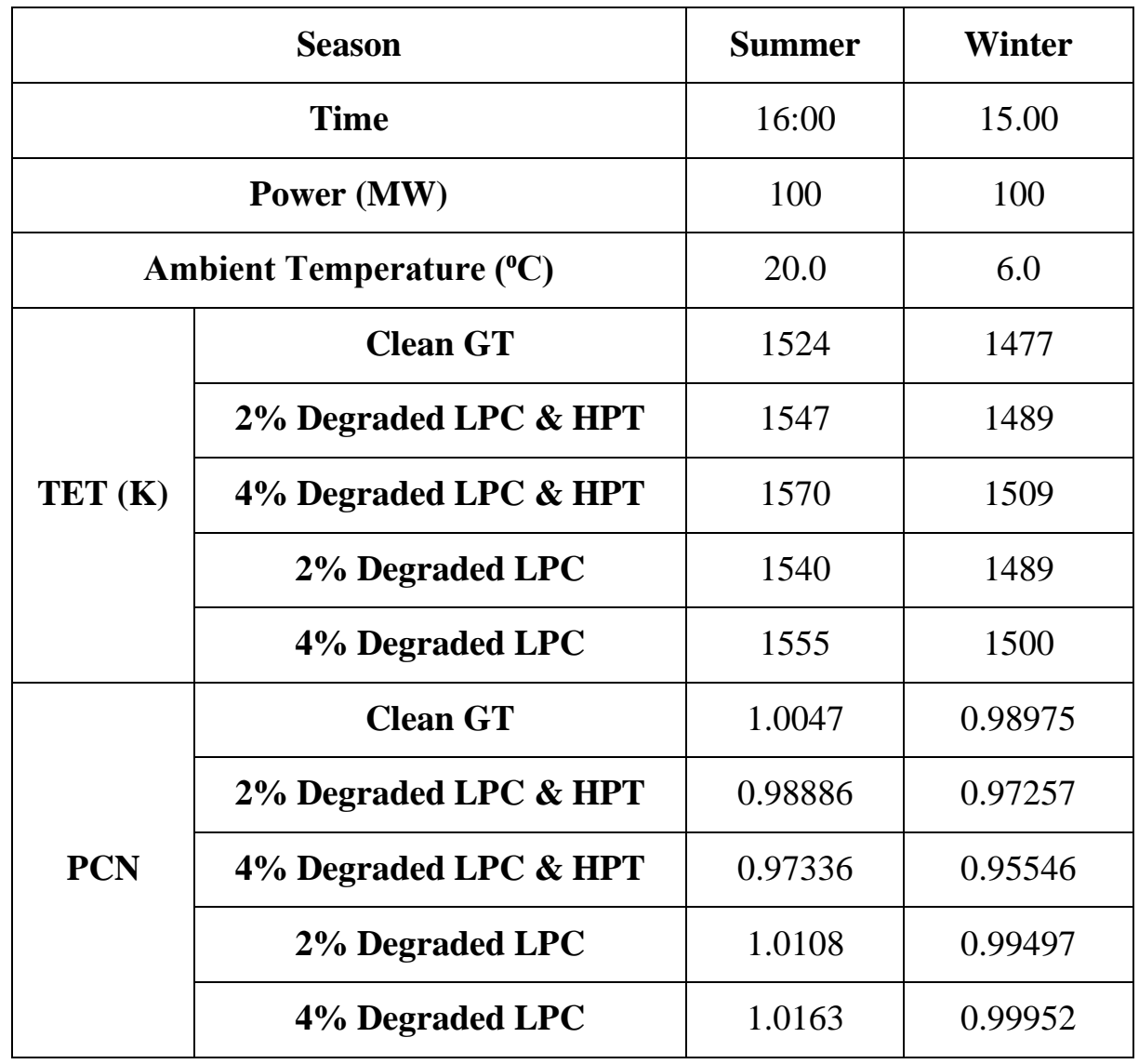

\section{Conclusion of results}

- From CCGT power demand charts in the UK it is clear that winter and summer have the greatest peak. During winter it is due to the increase in domestic heating demand in the evening, and due to the shortage of power production from wind turbines during the summer.

- For all seasons power demand is clearly lower in the night than in the day hours. Furthermore, spring, autumn and winter days have an evening peak due to domestic heating.

- Tc, TET, PCN and fuel-flow have positive correlation with both power setting and ambient temperature, whereas GT efficiency has positive correlation with power setting and negative correlation with ambient temperature.

- Degradation level in both LP compressor and HP turbine increases the TET significantly and the fuel flow slightly. 
- The higher degradation level in both LP compressor and HP turbine in the gas turbine has, the lower Tc and PCN occurs.

- TET, PCN and fuel flow have a positive correlation with degradation level in mass flow and component efficiency if the degradation exists in LP compressor only.

\section{References}

- Bonnie M.,2015,"Are Simple Cycles or Combined Cycles Better for Renewable Power Integration?", Available at: http://www.powermag.com/are-simple-cycles-or-combined-cyclesbetter-for-renewable-power-integration.

- DECC (Department of Energy and Climate Change). UK Renewable Energy Roadmap Update, Nov.2013,44-49. Available at: https://www.gov.uk/government/uploads/system/uploads/attachment_data/file/255182/UK_Rene wable_Energy_Roadmap_5_Nov._FINAL_DOCUMENT_FOR_PUBLICATIO.pdf.

- Reports BM. U.K. 2014, "National Grid Status", available at: http://www.gridwatch.templar.co.uk/.

- Ghafir MF a, Li. YG, Singh R, Huang K, Feng X. ,2010,"Impact of Operating and Health Conditions on Aero Gas Turbine Hot Section Creep Life Using a Creep Factor Approach". ASME ,1-13. Available at: DOI:10.1115/GT2010-22332.

- Ghafir A.2011 "Performance based creep life estimation for gas turbines application". Cranfield University; Available at: http://dspace.lib.cranfield.ac.uk/handle/1826/7457.

- Kassim A., 2013, "Impact of Operating Conditions and Compressor Degradation on Gas Turbine Performance", MSc thesis, Cranfield University, Bedfordshire, UK.

- Abu Turab Malik,2013, "Impact of Components Deterioration on Industrial Gas Turbine Performance", MSc. thesis, Crandfield University, Bedfordshire, UK.

- Lakshminarasimha A. N., Boyce M. P. and Meher-Homji C. B.,1994, "Modelling and Analysis of Gas Turbine Performance Deterioration", ASME Journal of Engineering for Gas Turbines and Power, 116:46-52.

- Diakunchak S ,1992, "Performance Deterioration in Industrial Gas Turbines", ASME Journal of Engineering for Gas Turbines and Power, 114:161-168.

- Hamed A. Tabakoff W, 2006, "Erosion and Deposition in Turbomachinery", Journal of Propulsion and Power, vol. 22, no. 2, pp. 350-360.

- Sugliano R,Pilidis P.,2005, "Techno-Economic Analysis of Different Filter Systems in Combination with Compressor Cleaning", MSc. Thesis, Cranfield University, Bedfordshire, UK. 
- WU.,2014,"Weather Underground",available at: http://www.underground.com.

- $\quad$ http://www.wunderground.com/?MR=1, (accessed 21/02). 